\title{
Polymer - Bonded Magnetic Materials with Various Nd-Fe-B Filler Content
}

\author{
A.S. Grujićc ${ }^{a, *}$, N.L. Lazić ${ }^{b}$, N.M. Talijan ${ }^{a}$, V. Spasojevićc ${ }^{c}$, J.T. StajiĆ-Trošić $^{a}$, \\ V.R. ĆOSOVIĆ ${ }^{a}$ AND R. AleKsiĆ ${ }^{d}$ \\ ${ }^{a}$ Institute of Chemistry, Technology and Metallurgy, Njegoševa 12, Belgrade, Serbia \\ ${ }^{b}$ Institute of General and Physical Chemistry, Studentski trg 12, Belgrade, Serbia \\ ${ }^{c}$ Institute of Nuclear Sciences "Vinča", Po Box 522, Belgrade, Serbia \\ ${ }^{d}$ Faculty of Technology and Metallurgy, Karnegijeva 4, Belgrade, Serbia
}

\begin{abstract}
One of the more important developments in magnetic materials, polymer bonded magnets, have opened a new world of application opportunities. The $\mathrm{Nd}-\mathrm{Fe}-\mathrm{B} /$ polymer composite materials offer an excellent combination of strong magnetic and dynamical-mechanical properties. However, the transition temperatures of filler and matrix should be selected carefully considering the future application. Uniform particle distribution and good adhesion between $\mathrm{Nd}-\mathrm{Fe}-\mathrm{B}$ powder particles and polymer are essential for the quality of the composite, while stiffness of polymer matrix is one of the influencing factors as well. The damping properties of $\mathrm{Nd}-\mathrm{Fe}-\mathrm{B} /$ polymer composites with 15 wt.\%, 50 wt.\% and 75 wt. $\%$ of $\mathrm{Nd}-\mathrm{Fe}-\mathrm{B}$ powder were studied by dynamic mechanical analysis and compared with a pure polymer sample. Thermal stability was analyzed using a simultaneous differential scanning calorimetric and thermogravimetric analysis technique.
\end{abstract}

PACS numbers: 75.50.Ww, 81.05.Qk, 83.85.Vb, 46.35.+z, 81.70.Pg, 91.60.Pn, 68.37.Hk

\section{Introduction}

Bonded magnets are engineered products whose properties can be tailored to suit a very wide variety of requirements and conventionally have been used in various fields, such as electric appliances and automobile parts $[1,2]$. The most important advantages of polymer bonded magnets are low weight, production of any shape and high dimensional accuracy i.e. near-net shape manufacture, good fracture toughness and corrosion resistance [3] as well as isotropic magnetization. Bonded magnets are produced by mixing of a magnetic material with a binder and processing that mixture into a finished product $[1,4,5]$.

The nanocrystalline magnetic materials based on rapidly solidified $\mathrm{Nd}-\mathrm{Fe}-\mathrm{B}$ alloys have been recently researched despite the poor $\mathrm{B}-\mathrm{H}$ loop squareness and poor coercivity Hci $(5 \mathrm{kOe}$ or $400 \mathrm{kA} / \mathrm{m}$ ) due to the fact that they contain up to three times smaller amount of expensive rare earth element $(\mathrm{Nd})$ comparing to conventional rapid-quenched and sintered $\mathrm{Nd}-\mathrm{Fe}-\mathrm{B}$ magnets [6]. High values of remanence are achieved when the iron content is increased and $\mathrm{Nd}_{2} \mathrm{Fe}_{14} \mathrm{~B} / \alpha$-Fe and $/$ or $\mathrm{Nd}_{2} \mathrm{Fe}_{14} \mathrm{~B} / \mathrm{Fe}_{3} \mathrm{~B}$ type nanocomposite microstructure is developed [4, 7]. Nanocomposite permanent magnets have been extensively studied because of their potential for production of bonded magnets [8, 9].

The various amounts of magnetic filler are employed to produce materials which exhibit significantly differ-

\footnotetext{
* corresponding author; e-mail: gruja@tmf.bg.ac.rs
}

ent magnetic and mechanical properties. Dynamic mechanical analysis (DMA) is probably the most sensitive single technique available for characterizing and interpreting the mechanical and curing behavior of polymers and polymer composites. The technique separates the viscoelasticity of a material into the two components of complex modulus $\left(E^{*}\right)$, a real part which is the elastic modulus $\left(E^{\prime}\right)$ and an imaginary part which is the damping or viscous component $\left(E^{\prime \prime}\right)$ and is expressed $E^{*}=E^{\prime}+\mathrm{i} E^{\prime \prime}[10]$.

As a consequence of the viscoelastic nature of polymer composites, their dynamic and thermal behavior is significantly dependent on strain, frequency and temperature. For bonded magnets, uniform particle distribution and good adhesion between $\mathrm{Nd}-\mathrm{Fe}-\mathrm{B}$ and polymer are important parameters which have significant influence on microstructure and stiffness of the final magnetic material.

In the work discussed in this paper materials have been characterized in term of their elastic (storage), damping (loss) properties and the ratio of the loss to storage modulus i.e. tan delta. The scope was to demonstrate the influence of weight amount of magnetic $\mathrm{Nd}-\mathrm{Fe}-\mathrm{B}$ filler on dynamic-mechanical, thermal and magnetic properties.

\section{Experimental}

Rapid quenched $\mathrm{Nd}-\mathrm{Fe}-\mathrm{B}$ powder with reduced content of neodymium was obtained by a centrifugal atomization method and then used to produce polymer bonded magnet samples. The chemical composition of the starting $\mathrm{Nd}-\mathrm{Fe}-\mathrm{B}$ alloy was: $\mathrm{Nd}-12$ mass \%, Pr-0.2 mass \%, B-4.2 mass \%, Al-0.3 mass \% and Fe-balance. The particles of the powder have characteristic 
angular shape with mean size of $87 \mu \mathrm{m}$. Used magnetic powder was fairly characterized in previous investigations [11-13] and its magnetic properties measured on a vibrating sample magnetometer after subsequent annealing at $660^{\circ} \mathrm{C} / 5 \mathrm{~min}$ are: remanence $\left(B_{\mathrm{r}}=10.9 \mathrm{kG}\right)$, coercivity $\left(H_{\mathrm{cb}}=2.7 \mathrm{kOe}, H_{\mathrm{cj}}=2.8 \mathrm{kOe}\right)$ and maximal energy product $\left((B H)_{\max }=10.7 \mathrm{MGOe}\right)$.

As a polymer matrix for magnetic composite materials preparation epoxy resin was used. The applied thermosetting epoxy system is combination of liquid mixture of Bisphenol $\mathrm{A}$ and Bisphenol $\mathrm{F}$ resins and cross linking agent (hardener) which cures fully at room temperature. The cured epoxy resin has tensile strength $\approx 58 \mathrm{MPa}$, elongation $\approx 2.8 \%$, compression strength $\approx 96 \mathrm{MPa}$, flexural strength $\approx 78 \mathrm{MPa}$ and density $\approx 1.2 \mathrm{~g} / \mathrm{cm}^{3}$.

Advanced composite materials were compression molded under a pressure of $4 \mathrm{MPa}$ at room temperature using a lab scale compression molding press. The molded sample was allowed to cure under a molding pressure about one day.

Observations of morphology of fracture surfaces of synthesized composite materials were made on the JEOL JSM-5800 Scanning Electron Microscope (SEM), with an accelerating voltage of $20 \mathrm{kV}$.

Thermal analyses of investigated $\mathrm{Nd}-\mathrm{Fe}-\mathrm{B} /$ epoxy composites as well as pure epoxy material were performed on SDT Q600, TA Instruments equipment for simultaneous differential scanning calorimetric (DSC) and thermogravimetric (TGA) analysis. The samples were heated at a rate of $5^{\circ} \mathrm{C} / \mathrm{min}$ in a nitrogen environment in temperature range ambient temperature up to $600^{\circ} \mathrm{C}$. Degradation temperature calculations ware performed from obtained data using the Universal analysis 2000 software.

A TA Instruments DMA Q800 was used to obtain dynamic mechanical data of investigated $\mathrm{Nd}-\mathrm{Fe}-\mathrm{B} /$ epoxy magnetic composites and pure epoxy sample. Storage modulus $\left(E^{\prime}\right)$, loss modulus $\left(E^{\prime \prime}\right)$ and tan delta i.e. ratio of $E^{\prime \prime} / E^{\prime}$ which is a measure of the material's damping effectiveness, were recorded as a function of temperature. The samples were tested using three-point bend clamp with a $20 \mathrm{~mm}$ span width and rectangular-edge probe, at a frequency of $1 \mathrm{~Hz}$ and displacement amplitude of $20 \mu \mathrm{m}$ ( $1 \%$ of sample thickness). Testing was done over a temperature range $25^{\circ} \mathrm{C}$ to $100{ }^{\circ} \mathrm{C}$ with a temperature ramp of $3{ }^{\circ} \mathrm{C} / \mathrm{min}$.

Magnetic properties of samples were measured at room temperature, on the Superconducting Quantum Interference Device (SQUID) magnetometer with magnetic field strength in range -5 up to $5 \mathrm{~T}$.

The presented investigations were undertaken in order to understand the effect of different content $(15,50$ and 75 wt.\%) of magnetic powder - filler on the thermal, dynamic mechanical and magnetic properties of the $\mathrm{Nd}-\mathrm{Fe}-\mathrm{B} /$ epoxy bonded magnetic materials.

\section{Results and discussion}

The good adhesion between polymer matrix and $\mathrm{Nd}-\mathrm{Fe}-\mathrm{B}$ powder is essential for the composites, espe- cially at temperatures above the glass transition temperature of the polymer $\left(T_{\mathrm{g}}\right)$. In addition, for permanent bonded magnets, the particle size of magnetic powder plays an important role in determination of powder to binder ratio, degree of particle alignment and magnetic and mechanical properties [14]. Generally speaking, the plate-like particles would result in higher packing density under the optimal compression conditions. [15, 16].

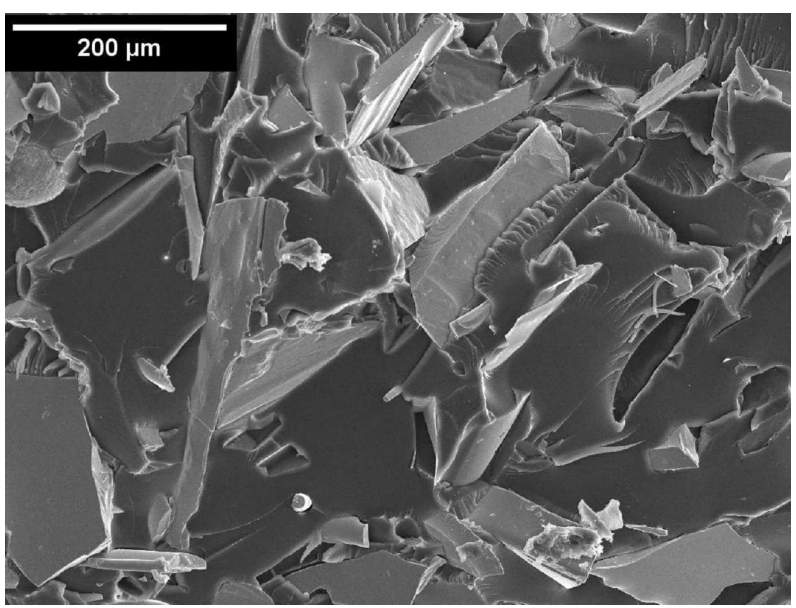

Fig. 1. SEM micrographs of fracture surface of $\mathrm{Nd}-\mathrm{Fe}-\mathrm{B} /$ epoxy composite material with $50 \mathrm{wt} . \%$ of $\mathrm{Nd}-\mathrm{Fe}-\mathrm{B}$ filler.

SEM micrograph of fracture surface morphology of $\mathrm{Nd}-\mathrm{Fe}-\mathrm{B} /$ epoxy composite is presented in Fig. 1. The $\mathrm{Nd}-\mathrm{Fe}-\mathrm{B}$ particles are shown as light grey and the epoxy matrix as dark. The darkest gray parts represent the holes ensued by pulling out of the $\mathrm{Nd}-\mathrm{Fe}-\mathrm{B}$ particles during the mechanical breaking (tension). Although the $\mathrm{Nd}-\mathrm{Fe}-\mathrm{B}$ particles are of variable size and shape, they seem to be attached rather well to the matrix.

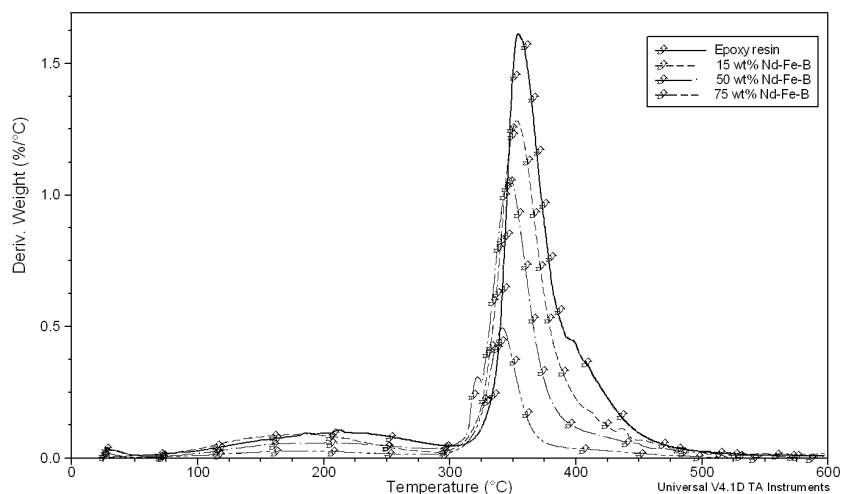

Fig. 2. TGA curves for the pure epoxy resin and the composites with 15 wt. $\%, 50$ wt. $\%$ and 75 wt. $\%$ of $\mathrm{Nd}-\mathrm{Fe}-\mathrm{B}$ filler.

The TGA curves for $\mathrm{Nd}-\mathrm{Fe}-\mathrm{B} /$ epoxy composite are shown in Fig. 2. TGA experiments were conducted to determine the degradation temperatures of magnetic com- 
posite materials. The temperature corresponding to the peak in the first derivative of weight percent with temperature, reported as degradation temperature $\left(T_{\mathrm{d}}\right)$, indicates the temperature corresponding to the highest rate of weight loss. The results of thermal degradation studies summarized in Table I clearly show that the samples with higher amount of magnetic filler have lower temperature of thermal degradation and lower degradation rate in regard to the pure epoxy resin.

TABLE I

Temperatures of thermal degradation obtained from TGA curves and DSC heat flow curves.

\begin{tabular}{c|c|c|c}
\hline \hline \multirow{2}{*}{ Sample } & TGA & \multicolumn{2}{|c}{ DSC } \\
\cline { 2 - 4 } & $T_{\mathrm{d}},\left[{ }^{\circ} \mathrm{C}\right]$ & $T_{\mathrm{d}},\left[{ }^{\circ} \mathrm{C}\right]$ & $\Delta H,[\mathrm{~J} / \mathrm{g}]$ \\
\hline Pure epoxy resin & 354.7 & 344.6 & 367.8 \\
15 wt.\% Nd-Fe-B & 353.5 & 339.3 & 182.2 \\
50 wt.\% Nd-Fe-B & 347.2 & 334.8 & 160.7 \\
75 wt.\% Nd-Fe-B & 340.0 & 331.5 & 75.6
\end{tabular}

The characteristic DSC curves for pure epoxy sample and $\mathrm{Nd}-\mathrm{Fe}-\mathrm{B} /$ epoxy composite materials are presented in Fig. 3. The results of investigation obtained by DSC method are in accordance with TGA measurements. The quantitative values of degradation temperatures and corresponding change of enthalpy are presented in Table I.

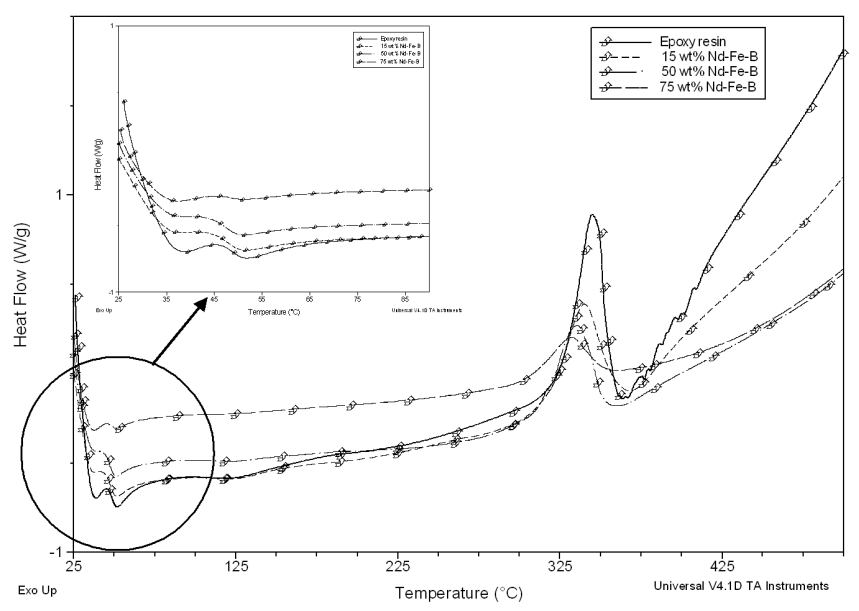

Fig. 3. Heat flow vs. temperature curves for the pure epoxy resin and the epoxy composites with 15 wt.\%, 50 wt.\% and 75 wt.\% of Nd-Fe-B filler.

DSC curves show an exothermal effect which appears between $300{ }^{\circ} \mathrm{C}$ and $380{ }^{\circ} \mathrm{C}$ and which refers to the reaction of thermal degradation or decomposition of the composite materials. The change of enthalpy which occurred during this process is decreased with increase of the concentration of added magnetic filler or with decrease of portion of epoxy matrix in composites.

Small endothermic effects, illustrated as a step transition, in temperature range between $45^{\circ} \mathrm{C}$ and $50{ }^{\circ} \mathrm{C}$ are referring to a glass transitions in the investigated composite materials [17]. The quantitative values of glass transition temperatures $T_{\mathrm{g}}$ obtained from DSC curves are presented in Table II. All investigated samples have very close values of glass transition temperatures which is confirmed by DMA measurements, also presented in Table II.

The dynamic mechanical properties of the pure epoxy polymer and $\mathrm{Nd}-\mathrm{Fe}-\mathrm{B} /$ epoxy magnetic composite materials were investigated in function of temperature, from the glassy to the rubbery state. Three points bending oscillatory testing is considered as pure mode of deformation and recommended for stiff materials.

The results show a significant improvement in the storage (elastic component) modulus caused by the presence of the $\mathrm{Nd}-\mathrm{Fe}-\mathrm{B}$ magnetic filler (Fig. 4). At the low temperature in glassy state, adding the $15 \mathrm{wt} . \%$ and $50 \mathrm{wt} . \%$ of $\mathrm{Nd}-\mathrm{Fe}-\mathrm{B}$ powder into epoxy matrix induced an increase of roughly $6 \%$ and $75 \%$ in storage modulus of pure epoxy polymer, respectively. Thus, the magnetic composite with 75 wt.\% of magnetic filler was found to have 3.2 times higher storage modulus than pure epoxy sample.

At the other end of temperature range, the storage modulus decreases with the temperature to the lower values in the, so called, rubbery state [18]. However, in this state, the magnetic filler also induces significant improvement of storage modulus. Comparing to pure epoxy sample values of storage modulus are 1.7, 2.9 and 9.1 times higher for composites with $15 \mathrm{wt} . \%, 50 \mathrm{wt} . \%$ and $75 \mathrm{wt} . \%$ of $\mathrm{Nd}-\mathrm{Fe}-\mathrm{B}$ content, respectively.

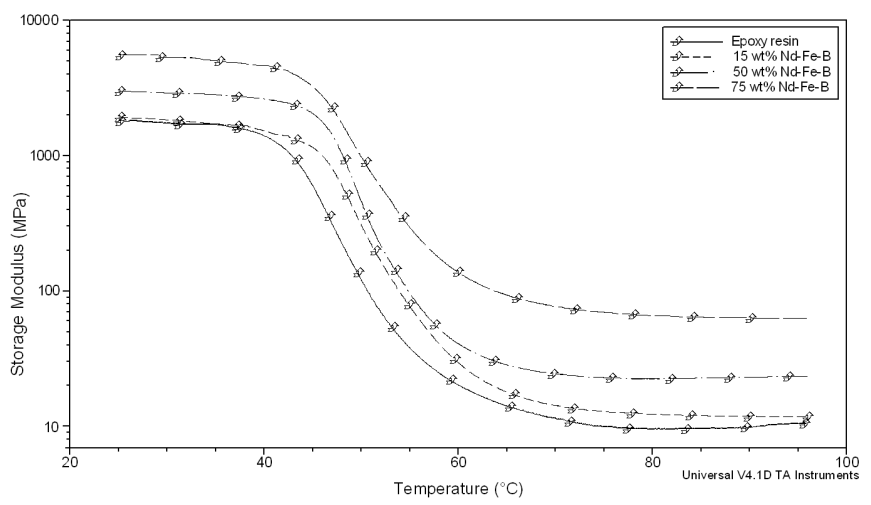

Fig. 4. DMA curves of storage modulus $E^{\prime}$, for the pure epoxy resin and the epoxy composites with 15 wt. $\%, 50$ wt. $\%$ and 75 wt.\% of $\mathrm{Nd}-\mathrm{Fe}-\mathrm{B}$ filler versus temperature.

In the glassy region, the contribution of the filler to the dynamic modulus can be expressed as:

$$
E_{\mathrm{T}}=E_{1} c_{1}+A E_{2} c_{2},
$$

where $E_{\mathrm{T}}$ is the total dynamic modulus, $E_{1}$ is the modulus of the pure polymer, $E_{2}$ is the modulus of the filler, $c_{1}$ and $c_{2}$ are volume fractions involved $\left(c_{1}+c_{1}=1\right)$, and $A$ is an adhesion factor between the filler and poly- 


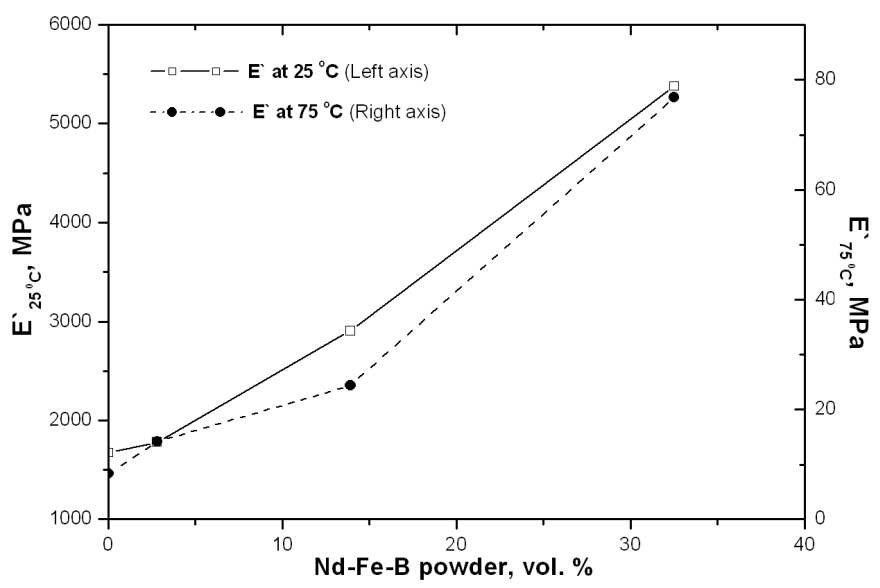

Fig. 5. Storage modulus $E^{\prime}$ at $25^{\circ} \mathrm{C}$ and $75^{\circ} \mathrm{C}$ of the pure epoxy resin and the $\mathrm{Nd}-\mathrm{Fe}-\mathrm{B} /$ epoxy composites as a function of filler concentration.

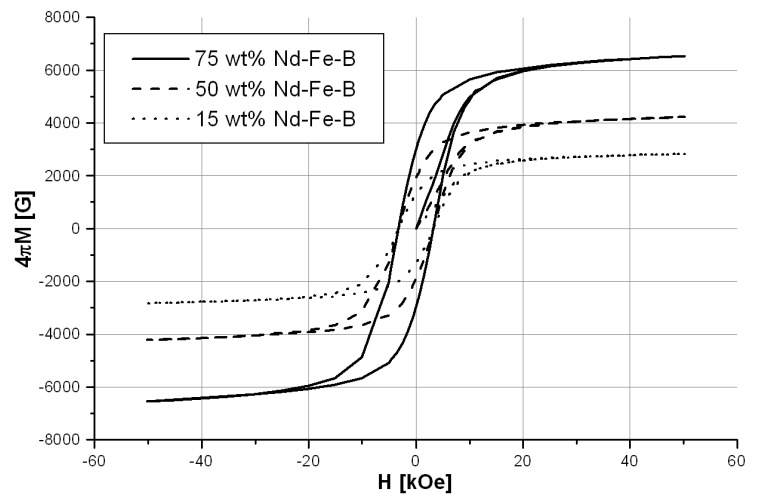

Fig. 6. Hysteresis loops of magnetic composites with 15 wt. $\%, 50$ wt. $\%$ and 75 wt. $\%$ of $\mathrm{Nd}-\mathrm{Fe}-\mathrm{B}$ filler in epoxy matrix. mer [19-22]. In the rubbery region, approximately above $70{ }^{\circ} \mathrm{C}$, dynamic storage modulus may be expressed as:

$$
E_{\text {filled composite }}^{\prime}=E_{\text {pure polymer }}^{\prime} f(f, c) F(A)
$$

Parameters in Eq. (2) are $f(f, c)$ - the hydrodynamic effect, well-known to be dependent on the shape factor $f$, of the filler particles or agglomerates and the volume concentration $c$, of the filler. The parameter $F(A)$ refers to the interaction of filler with polymer.

The significant enhancement of the storage modulus of $\mathrm{Nd}-\mathrm{Fe}-\mathrm{B} /$ epoxy composites in the rubbery region above $75^{\circ} \mathrm{C}$ could be explained by the variable size and shape of $\mathrm{Nd}-\mathrm{Fe}-\mathrm{B}$ particles resulting in higher packing density, good particle to particle interaction and attachment to the epoxy matrix (Fig. 5).

The magnetic behavior of investigated magnetic composite materials is presented, with corresponding SQUID hysteresis loops, in Fig. 6. The shape of hysteresis loop is characteristic for $\mathrm{Nd}-\mathrm{Fe}-\mathrm{B}$ materials with reduced $\mathrm{Nd}$ content [23]. This type of rare-earth materials is often called high remanence magnetic materials because of their high values of remanence $\left(B_{\mathrm{r}}\right)$, which has a direct influence on high values of maximal energy product $\left(B H_{\max }\right)$.

The presented hysteresis loops illustrate the substantial difference between three obtained composite materials with different content of $\mathrm{Nd}-\mathrm{Fe}-\mathrm{B}$ particles in epoxy matrix. It is obvious that composite materials with higher amount of magnetic powder have improved magnetic properties.

TABLE II

Glass transition temperatures obtained from DSC and DMA curves.

\begin{tabular}{c|c|c|c|c|c|c}
\hline \hline & \multicolumn{4}{|c|}{ Glass Transition Temperature $\left(T_{\mathrm{g}}\right),\left[{ }^{\circ} \mathrm{C}\right]$} \\
\cline { 2 - 7 } & \multicolumn{3}{|c|}{ DSC } & \multicolumn{3}{c}{ DMA $\left(E^{\prime}\right)$} \\
\hline Sample & Onset & Offset & Midpoint & Onset & Offset & Midpoint \\
\hline Pure epoxy resin & 46.8 & 50.6 & 48.3 & 39.4 & 48.0 & 43.7 \\
15 wt.\% Nd-Fe-B & 45.0 & 49.7 & 47.2 & 43.4 & 50.8 & 47.1 \\
50 wt.\% Nd-Fe-B & 44.4 & 49.3 & 47.0 & 44.0 & 50.5 & 47.5 \\
75 wt.\% Nd-Fe-B & 46.9 & 49.8 & 48.4 & 42.8 & 51.2 & 46.8
\end{tabular}

\section{Conclusion}

Bonded magnets with 15 wt. $\%, 50$ wt. $\%$ and 75 wt.\% content of $\mathrm{Nd}-\mathrm{Fe}-\mathrm{B}$ powder in epoxy matrix were pro- duced and studied. The degradation temperatures obtained using TGA/DSC analyses show enhancement for samples with higher amount of epoxy matrix. On the other side, glass transition temperatures obtained from 
DSC curves and from storage modulus curves (DMA) suggest that there are no significant changes in glass transition temperatures of composites. The obtained experimental results also show considerable improvement in the storage (elastic component) modulus caused by the presence of the $\mathrm{Nd}-\mathrm{Fe}-\mathrm{B}$ magnetic filler at low temperatures in glassy state, as well as in rubbery state at higher temperatures. As expected, magnetic properties are drastically enhanced with higher amount of $\mathrm{Nd}-\mathrm{Fe}-\mathrm{B}$ magnetic powder.

In addition, this study provides a method for tailoring the properties of epoxy bonded magnets in general, especially for the automobile and information technology applications where the relatively brittle metallic permanent magnets are not useable.

\section{Acknowledgments}

This work has been supported by the Ministry of Science and Technological Development of the Republic of Serbia under Projects: OI 142035 B and OI 166007 G.

\section{References}

[1] D. Brown, Bao-Min Ma, Z. Chen, J. Magn. Magn. Mater. 248, 432 (2002).

[2] J. Li, Y. Liu, S.J. Gao, M. Li, Y.Q. Wang, M.J. Tu, J. Magn. Magn. Mater. 299, 195 (2006).

[3] L.A. Dobrzanski, M. Drak, J. Alloy. Compd. 449, 88 (2008).

[4] D.N. Brown, Z. Chen, P. Guschl, P. Campbell, J. Magn. Magn. Mater. 303, e371 (2006).

[5] B.M. Ma, J.W. Herchenroeder, B. Smith, M. Suda, D. Brown, Z. Chen, J. Magn. Magn. Mater. 239, 418 (2002).

[6] D. Goll, H. Kronmüller, Naturwissenschaften 87, 423 (2000).
[7] E.F. Kneller, R. Hawig, IEEE Trans. Magn. 27, 3589 (1991).

[8] C. Wang, M. Yan, W.Y. Zhang, Mat. Sci. Eng. B 123, 80 (2005).

[9] A. Manaf, R.A. Buckley, H.A. Davies, M. Leonowicz, J. Magn. Magn. Mater. 101, 360 (1991).

[10] J.D. Fery, Viscoelastic Properties of Polymers, 3rd edition, John Wiley \& Sons, New York 1980.

[11] V. Ćosović, N. Talijan, A. Grujić, J. Stajić-Trošić, T. Žák, Z. Lee, V. Radmilović, Sci. Sint. 41, 209 (2009).

[12] V. Ćosović, T. Žák, N. Talijan, A. Grujić, J. Stajić-Trošić, J. Alloy. Compd. 456, 251 (2008).

[13] N. Talijan, V. Ćosović, J. Stajić-Trošić, A. Grujić, T. Žák, Z. Lee, V. Radmilović, Mater. Trans. 50, 2302 (2009).

[14] M. Kokabi, F. Arabgol, M. Manteghian, Iran. Polym. J. 14, 71 (2005).

[15] D. Rodrigues, G.V. Concilio, F.J.G. Landgraf, A.C. Zanchetta, in: Proc. of the 14th International Workshop Rare-Earth Magnets and Their Applications, Eds. F.P. Missell, V. Villas-Boas, H.R. Rechenberg, F.J.G. Landgraf, Sao Paulo 1996, Vol. 1 p. 580.

[16] X.H. Zhang, W.H. Xiong, Y.F. Li, N. Song, Mater. Design 30, 1386 (2009).

[17] T. Maity, B.C. Samanta, S. Dalai, A.K. Banthia, Mat. Sci. Eng. A 464, 38 (2007).

[18] S. Denga, M. Houb, L. Yea, Polym. Test. 26, 803 (2007).

[19] A.R. Payne, in: Reinforcement of Elastomers, Ed. G. Kraus, Interscience Publisher, New York 1965.

[20] M.J. Wang, Rubber Chem. Technol. 72, 430 (1999).

[21] M.J. Wang, Kautsch, Gummi Kunstst. 61, 33 (2008).

[22] N.M. Alves, J.L. Gomez Ribelles, J.A. Gomes Tejedor, J.F. Mano, Macromolecules 37, 3735 (2004).

[23] A. Grujić, T. Žák, V. Ćosović, J. Stajić-Trošić, V. Spasojević, N. Talijan, Optoelectron. Adv. M.-R.C. 3, 477 (2009). 